L. Parvaneh ${ }^{1,2}$, N. Sharifi² ${ }^{2}$, G. Azizi ${ }^{3}$, H. Abolhassani ${ }^{2}$, L. Sharifi ${ }^{4}$, A. Mohebbi ${ }^{5}$, E. Bahraminia ${ }^{2}$, S. Delavari ${ }^{2}$, M. Alebouyeh ${ }^{6}$, E. Tajeddin ${ }^{6}$, S.R. Mohebbi $^{6}$, R. Yazdani ${ }^{2}$, N. Behniafard ${ }^{7}$, A. Aghamohammadi ${ }^{2}$

\title{
Infectious etiology of chronic diarrhea in patients with primary immunodeficiency diseases
}

\author{
${ }^{1}$ Department of Biology, Central Tehran Branch, Islamic Azad University, Tehran, Iran \\ ${ }^{2}$ Research Center for Immunodeficiencies, Pediatrics Center of Excellence, Children's Medical Center, Tehran University of \\ Medical Sciences, Tehran, Iran \\ ${ }^{3}$ Non-communicable Diseases Research Center, Alborz University of Medical Sciences, Karaj, Iran \\ ${ }^{4}$ Uro-Oncology Research Center, Tehran University of Medical Sciences, Tehran, Iran \\ ${ }^{5}$ Growth and Development Research Centre, Paediatrics Centre of Excellence, Children's Medical Centre, Tehran University \\ of Medical Sciences, Tehran, Iran \\ ${ }^{6}$ Foodborne and Waterborne Diseases Research Center, Research Institute for Gastroenterology and Liver Diseases, Shahid \\ Beheshti University of Medical Sciences, Tehran, Iran \\ ${ }^{7}$ Department of Pediatrics, Shahid Sadoughi University of Medical Sciences, Yazd, Iran
}

\section{KEY WORDS}

primary immunodeficiency disease; common variable immunodeficiency;

hyper-IgM syndrome; severe combined immunodeficiency; X-linked agammaglobulinemia; infection

\section{Corresponding Author}

Asghar Aghamohammadi

Children's Medical Center Hospital

62 Qarib St., Keshavarz Blvd., Tehran

14194, Iran

Phone: + 982166428998

Fax: + 982166923054

E-mail: aghamohammadi@sina.tums.ac.ir

Doi

10.23822/EurAnnACI.1764-1489.77

\begin{abstract}
Summary
Background. Primary immunodeficiency diseases (PIDs) are life-threatening disorders, which manifest commonly with gastrointestinal (GI) signs, mainly as chronic diarrhea. Objective. To investigate and compare infectious etiology of chronic diarrhea in different PIDs. Patients and methods. Assessing clinical features, obtaining immunological profiles, as well as characterizing infectious etiology of diarrhea were performed in 38 PID patients with chronic diarrhea. Stool samples andlor biopsy specimens were checked using culture, microscopic examination, RT-PCR, and PCR, as appropriate. The patients were diagnosed to have common variable immunodeficiency (CVID), severe combined immunodeficiency (SCID), X-linked agammaglobulinemia (XLA), and hyper-IgM (HIgM) syndrome. Results. In 32 patients we identified 41 infectious agents including 16 parasitic (39.0\%, the most common Giardia lamblia), 11 bacterial (26.8\%, the most common salmonella spp), 8 viral (19.5\%, the most frequent group $A$ rotavirus), and 6 fungal organisms (14.7\%, the most common Candida albicans). From 6 of the patients, no infectious agent was isolated. In CVID bacteria and parasites, in SCID bacteria and viruses, in XLA parasites, and in individuals with HIgM syndrome parasites were the leading causes of chronic diarrhea. Infection with giardia and cryptosporidium were more frequent in XLA and HIgM, respectively. Conclusion. The current study suggests considering both usual and unusual pathogens in laboratory investigation and in the empiric treatment of chronic diarrhea. Opportunistic pathogens should be taken into account when no other pathogen is identified, especially in patients on long-term treatment or prophylaxis with antifungals/antibiotics and in those from geographical locations that favor pathogenicity of these organisms.
\end{abstract}




\section{Introduction}

Primary immunodeficiency diseases (PIDs) are a heterogeneous group of genetic disorders affecting the development and/or function of the immune system with an overall prevalence of 1 in 10,000 live births (1). The patients are susceptible to autoimmune diseases, malignancies, as well as infections, especially of respiratory and gastrointestinal (GI) tracts. GI problems are the second most common manifestations of PID after respiratory problems and may be the first presentations in some cases. Among different GI complications, chronic diarrhea is the most common, arising from non-infectious as well as infectious etiologies. PID patients are more prone to diarrhea, due to a wide range of pathogens, and less responsive to standard therapies than healthy individuals. Moreover, intestinal damages and loss of nutrients and proteins worsen immune status and trigger a vicious circle that deteriorates immune defects. Elucidating infectious agents responsible for diarrhea in these patients, helps both precise laboratory investigation of suspected pathogens and subsequent correct diagnosis and treatment, leading to more survival, less mortality, and better life quality with fewer organ damages (2-4). The aim of the present study was to determine infectious etiology of chronic diarrhea in PID individuals.

\section{Patients and methods}

\section{Patients}

Iranian Primary Immunodeficiency Registry (IPIDR) has been active since 1997 , and 1640 cases with a variety of PIDs were registered up to the end of 2014 (5). Within patients referred to Children's Medical Center (CMC) hospital in Tehran from January 2013 through June 2014, PID was diagnosed in 147 individuals. Among them, 38 patients with chronic diarrhea were included in the study. The study was approved by the ethics committee of Tehran University of Medical Sciences in accordance with the ethical standards. The participating patients or their parents were also given verbal information before taking their written informed consent. The diagnosis of PID was based on the European Society for Immunodeficiencies and the Pan-American Group for Immunodeficiency (ESID/PAGID) criteria (6). Chronic diarrhea was defined as the production of loose stool more than $10 \mathrm{~mL} / \mathrm{kg} /$ day in infants or more than $200 \mathrm{~g}$ in other ages that last more than 2 weeks (7).

\section{Data Collection}

A questionnaire was designed to obtain information, including patient's demographic information such as age, sex, date of birth, place of birth, diagnosis of PID, course of PID, immunological laboratory results, and diarrhea data. All of the questionnaires were completed by physicians involved in the care of the reported patients.

\section{Laboratory testing}

Immunological laboratory tests were performed. Moreover, stool samples and biopsy specimens were taken and checked for bacterial culture and also looked for Clostridium difficile ( $C$. difficile) toxin, Clostridium perfringens ( $C$. perfringens) toxin, parasites, and fungi/yeast-like organisms. Enteroviruses as well as group A rotavirus was checked using RT-PCR method, and cytomegalovirus (CMV) using PCR.

\section{Statistical analysis}

Fisher's exact test and chi-square tests were used for $2 \times 2$ comparison of categorical variables, whereas t-tests and one-way ANOVA were used to compare numerical variables. Statistical analysis was performed using the SPSS software package, version 17 (SPSS Inc., Chicago, IL, USA). A p-value $<0.05$ was considered significant.

\section{Results}

\section{Demographic and clinical information}

From 147 PID patients evaluated, 38 patients fulfilled the criteria for chronic diarrhea $(81.6 \%$ male $)$ and enrolled in the study during the 18 month period of the study. No sign of dysentery was observed. The median age of patients at the time of the study was 12 (3.3-22.0) years. According to ESID/PAGID criteria (6), patients were diagnosed as having common variable immunodeficiency (CVID) ( $\mathrm{n}=12 ; 31.6 \%$ ), severe combined immunodeficiency (SCID) ( $\mathrm{n}=11 ; 28.95 \%)$, X-linked agammaglobulinemia (XLA) ( $\mathrm{n}=11 ; 28.95 \%)$, and hyper-IgM $(\mathrm{HIgM})$ syndrome $(\mathrm{n}=4 ; 10.5 \%)$. Statistical analysis did not show any significant correlation between age at first diarrhea and age at onset or age at diagnosis of PID. Demographic information, as well as immunological laboratory data and diarrhea information of the study population, are illustrated in tables I and II, respectively.

Table I - Demographic data of PID patients with chronic diarrhea.

\begin{tabular}{cc}
\hline Parameter & Results \\
\hline sex, $\mathrm{m} / \mathrm{f}$ & $31 / 7$ \\
\hline age, $\mathrm{y}$ & $12.0(3.3-22.0)$ \\
\hline age at onset of PID symptoms, y & $0.6(0.2-1.8)$ \\
\hline age at diagnosis of PID, y & $3.0(1.0-7.5)$ \\
\hline age at first diarrhoea, y & $2.00(0.5-7.3)$
\end{tabular}

PID, primary immunodeficiency; $f$, male; $f$, female; $y$, year. For quantitative parameters, the median is shown (with 25 th and 75 th percentiles). 
Table II - Clinical and immunological data of PID patients with chronic diarrhea.

\begin{tabular}{|c|c|c|c|c|c|c|c|c|}
\hline \multirow{2}{*}{$\begin{array}{l}\text { Diagnosis } \\
\text { (number of } \\
\text { patients) }\end{array}$} & \multicolumn{3}{|c|}{ Ig level (mg/dL); median (IQR) } & \multicolumn{4}{|c|}{ CD (\%); median (IQR) } & \multirow{2}{*}{$\begin{array}{c}\text { Age at first } \\
\text { diarrhea, y; } \\
\text { median (IQR) }\end{array}$} \\
\hline & $\operatorname{IgM}$ & IgG & $\operatorname{Ig} A$ & $\mathrm{CD}^{+}$ & $\mathrm{CD}^{+}$ & $\mathrm{CD}^{+}$ & $\mathrm{CD} 19^{+}$ & \\
\hline CVID (12) & $\begin{array}{c}18.0 \\
(4.0-80.0)\end{array}$ & $\begin{array}{c}114.0 \\
(68.0-570.0)\end{array}$ & $\begin{array}{c}5.0 \\
(0-13.0)\end{array}$ & $\begin{array}{c}74.0 \\
(65.5-82.0)\end{array}$ & $\begin{array}{c}23.0 \\
(10.5-29.0)\end{array}$ & $\begin{array}{c}52.0 \\
(36.5-62.5)\end{array}$ & $\begin{array}{c}6.5 \\
(2.7-13.3)\end{array}$ & $\begin{array}{c}3.0 \\
(0.5-13.0)\end{array}$ \\
\hline SCID (11) & $\begin{array}{c}27.0 \\
(10.0-150.0) \\
\end{array}$ & $\begin{array}{c}156.0 \\
(99.0-570.0)\end{array}$ & $\begin{array}{c}7.0 \\
(0.0-129.3)\end{array}$ & $\begin{array}{c}2.9 \\
(0.5-10.9)\end{array}$ & $\begin{array}{c}1.4 \\
(0.1-19.5)\end{array}$ & $\begin{array}{c}1.8 \\
(0.4-11.8)\end{array}$ & $\begin{array}{c}32.7 \\
(0.2-86.3)\end{array}$ & $\begin{array}{c}0.5 \\
(0.3-0.8)\end{array}$ \\
\hline XLA (11) & $\begin{array}{c}20.0 \\
(0.0-26.0)\end{array}$ & $\begin{array}{c}112.0 \\
(10.0-290.0)\end{array}$ & $\begin{array}{c}11.5 \\
(0.5-39.5)\end{array}$ & $\begin{array}{c}90.4 \\
(71.9-93.2)\end{array}$ & $\begin{array}{c}44.9 \\
(25.3-51.3)\end{array}$ & $\begin{array}{c}37.5 \\
(25.5-45.9)\end{array}$ & $\begin{array}{c}0.2 \\
(0.1-1.2)\end{array}$ & $\begin{array}{c}2.0 \\
(1.0-9.3)\end{array}$ \\
\hline HIgM (4) & $\begin{array}{c}256.0 \\
(94.0-727.5)\end{array}$ & $\begin{array}{c}56.0 \\
(3.8-205.8)\end{array}$ & $\begin{array}{c}10.0 \\
(3.0-22.0)\end{array}$ & $\begin{array}{c}76.5 \\
(65.0-83.5)\end{array}$ & $\begin{array}{c}42.0 \\
(30.0-56.3)\end{array}$ & $\begin{array}{c}29.5 \\
(21.0-40.3)\end{array}$ & $\begin{array}{c}15.1 \\
(8.9-18.2)\end{array}$ & $\begin{array}{c}2.5 \\
(0.5-4.5)\end{array}$ \\
\hline p-value & 0.059 & 0.325 & 0.754 & $<0.001^{1}$ & $0.002^{1}$ & $<0.001^{1}$ & $0.002^{1}$ & 0.082 \\
\hline
\end{tabular}

CVID, common variable immunodeficiency; HIgM, hyper IgM syndrome; PID, primary immunodeficiency; SCID, severe combined immunodeficiency; XLA, $\mathrm{X}$-linked agammaglobulinemia. For quantitative parameters the median is shown (with 25th and 75th percentiles). Kruskal-Wallis test was used to compare parameters. ${ }^{1} \mathrm{~A}$ p-value of 0.05 or less is statistically significant.

\section{Infectious etiology}

From 32 PID patients, 41 infectious agents were isolated and recognised as causes of diarrhea, including 16 parasitic (39.0\%, the most common Giardia lamblia; G. lamblia), 11 bacterial (26.8\%, the most common Salmonella spp.), 8 viral (19.5\%, the most common group A rotavirus), and 6 fungal/ yeast like agents $(14.7 \%$, the most frequent Candida albicans; C. albicans) (table III). Detailed information on infectious agents in each PID is represented in table III. From 6 of the patients (3 SCID and 3 CVID individuals) no infectious agent was isolated, however, in CVID patients, two were diagnosed with IBD and another with celiac disease.

Regarding infectious etiology of diarrhea within each PID group, 16 infectious agents were isolated from CVID patients. Bacterial and parasitic organisms were leading pathogens, and viral and fungal agents were in the second order of frequency. From SCID subjects, 8 pathogens were isolated; among them, bacteria and viruses were the most common. However, a fungus/yeast was also isolated. In XLA individuals 12 infectious agents were recognized; among them, parasites were obviously dominant, followed by fungal, bacterial, and viral pathogens. And finally, from HIgM patients 5 organisms were isolated as causes of diarrhea, while parasites were dominant followed by viral etiology (table III). Fisher exact test showed that Giardia infections were significantly more frequent in XLA compared with other PIDs ( $\mathrm{p}=0.001)$. Moreover, the frequency of Cryptosporidium infection was significantly higher in HIgM compared with other PIDs $(\mathrm{p}=0.009)$.

\section{Discussion}

GI problems, especially chronic infectious diarrhea, are among common manifestations in PID patients necessitating unraveling underlying etiology. Different parasitic, bacterial, viral, and fungal/yeast-like organisms have been reported as responsible causes. Defects in nutrient absorption caused by diarrhea in PID patients, via impairing structure and function of immune components, poses affected individuals to the higher risk of immune disturbances. Considering the consequences of GI complications for PID patients, and the necessity for correct diagnosis with subsequent proper treatment, we aimed to investigate infectious etiology of chronic diarrhea in different PIDs $(3,8)$. In our CVID patients, frequent pathogens were bacterial (including Salmonella spp.) and parasitic (including G. lamblia), and with less frequencies, viral (group A rotavirus and CMV) and fungal (C. albicans) (table III). Cunningham-Rundles and Bodian reported parasitic (Giardia) and bacterial pathogens (Campylobacter and Salmonella spp.) as the main causes of diarrhea in CVID patients, however, a viral organism (CMV) was also isolated (9). McCabe reported Giardia as infectious agent associated with CVID (10). In our previous cohort of 83 Iranian humoral immunodeficient patients, including CVID cases, $G$. lamblia followed by Salmonella spp. were prevalent pathogens (11). In a French study on CVID patients, bacterial (including Salmonella spp.) followed by parasitic pathogens (Giardia) were leading causes (12). Our results are in accordance with organisms reported by other studies. Moreover, less frequent pathogens were isolated from our patients such as enterotoxigenic $C$. 
Table III - Infectious etiology of chronic diarrhea in different PID patients.

\begin{tabular}{|c|c|c|c|c|c|c|}
\hline \multirow[b]{2}{*}{ Infectious organism } & \multicolumn{6}{|c|}{ Number of infectious agents in each type of PID } \\
\hline & total & CVID & SCID & XLA & HIgM & p-value \\
\hline parasites & 16 & 5 & - & 7 & 4 & $<0.001^{1}$ \\
\hline Giardia lamblia & 9 & 1 & - & 7 & 1 & $0.001^{1}$ \\
\hline Cryptosporidium spp. & 2 & - & - & - & 2 & $0.009^{1}$ \\
\hline Blastocystis hominis & 1 & - & - & - & 1 & 0.1 \\
\hline Fasciola spp. & 1 & 1 & - & - & - & 1.0 \\
\hline hookworm & 1 & 1 & - & - & - & 1.0 \\
\hline Schistosoma spp. & 1 & 1 & - & - & - & 1.0 \\
\hline Trichostrongylus spp. & 1 & 1 & - & - & - & 1.0 \\
\hline bacteria & 11 & 6 & 4 & 1 & - & 0.09 \\
\hline Salmonella spp. & 5 & 2 & 2 & 1 & - & 1.0 \\
\hline Clostridium difficile & 1 & 1 & - & - & - & 1.0 \\
\hline Pseudomonas aeruginosa & 2 & - & 2 & - & - & 0.35 \\
\hline Enterotoxigenic Clostridium perfringens & 1 & 1 & - & - & - & 1.0 \\
\hline Fusobacterium spp. & 1 & 1 & - & - & - & 1.0 \\
\hline Shigella spp. & 1 & 1 & - & - & - & 1.0 \\
\hline viruses & 8 & 3 & 3 & 1 & 1 & 0.72 \\
\hline group $\mathrm{A}$ rotavirus & 5 & 1 & 3 & - & 1 & 0.18 \\
\hline enterovirus (non-polio) & 1 & 1 & - & - & - & 1.0 \\
\hline poliovirus (VDPV) & 1 & - & - & 1 & - & 0.64 \\
\hline cytomegalovirus & 1 & 1 & - & - & - & 1.0 \\
\hline fungi/yeasts & 6 & 2 & 1 & 3 & - & 0.66 \\
\hline Candida albicans & 5 & 2 & 1 & 2 & - & 1.0 \\
\hline Trichosporon spp. & 1 & - & - & 1 & - & 0.68 \\
\hline
\end{tabular}

CVID, common variable immunodeficiency; HIgM, hyper IgM syndrome; PID, primary immunodeficiency; SCID, severe combined immunodeficiency; VDPV, vaccine-derived poliovirus; XLA, X-linked agammaglobulinemia.

${ }^{1} \mathrm{~A}$ p-value of 0.05 or less is statistically significant.

perfringens and Fusobacterium spp. among bacteria, and C. albicans as fungus. However, our patients were children or young adults (not older than 22 years), and this could be a bias at least for CVID patients.

In SCID individuals we found bacterial (including Salmonella spp.) and viral (group A rotavirus) pathogens as the main etiology (table III). Other studies reported various viral etiologies including rotaviruses, $\mathrm{CMV}$, astroviruses and noroviruses from SCID individuals $(8,13-15)$. Bacterial etiology is another reported cause of diarrhea in SCID patients (3). We also observed, as opportunistic causes of diarrhea, Pseudomonas aeruginosa (P. aeruginosa) among bacteria, and $C$. albicans among fungi.

In our XLA patients, parasites (the only found organism was $G$. lamblia) obviously predominate, whereas with a less frequency fungal, bacterial (Salmonella), and viral pathogens (vaccine-derived poliovirus; VDPV) were also isolated (table III). Two relatively uncommon pathogens isolated from our patients were C. albicans and Trichosporon spp. belonging to the fungal/yeast- like type of organisms. Giardia infection was significantly more frequent in XLA compared with other PIDs. In our previous study, we observed Giardia as the sole infectious agent in XLA patients (11). In another cohort of Iranian XLA patients, we isolated bacteria (including Shigella spp.), followed by parasites (including G. lamblia) as causative organisms (16). In an American cohort of XLA individuals, parasites (G. lamblia), followed by bacteria (including Salmonella spp.), and viruses (rotavirus, enterovirus) were isolated (17).

In the current study, in HIgM individuals parasitic pathogens were including G. Lamblia, Blastocystis hominis and Cryptosporidium spp. However, a viral pathogen (group A rotavirus) was also isolated. Cryptosporidium infection had a significantly higher frequency in HIgM compared with other PIDs. Our results are in accordance with the results reported by Winkelstein et al., who observed parasites (Cryptosporidium and G. lamblia) as the main infectious etiology of diarrhea, followed by viruses (rotavirus) and bacteria in HIgM individuals (18). 
Altogether, our results regarding infectious etiology of chronic diarrhea are in line with above-mentioned studies. In CVID patient's parasites and bacteria, in SCID viruses and bacteria, in XLA individuals parasites and fungi, and in patients with HIgM syndrome parasites, were most frequent etiologies. However, some differences appear: 1) order of organism types responsible for diarrhea in some PIDs. For example, in our SCID patients bacterial and viral pathogens had equal contribution in eliciting diarrhea, but in some other studies viral pathogens predominate. This could be due to some limitations in our study for laboratory investigation of all possible viral causes of diarrhea. 2) We isolated the same types of pathogens reported by previous studies, but within these pathogens some opportunistic or unusual organisms were also identified, including enterotoxigenic C. perfringens, P. aeruginosa, and Fusobacterium spp. among bacteria. 3) Moreover, we identified C. albicans and Trichosporon spp., two relatively unusual causes of diarrhea as fungal/yeast etiology. Though not frequently, the unusual infectious agents were reported by other studies, and well documented as opportunistic causes of diarrhea even in immunocompetent individuals. Enterotoxigenic $C$. perfringens has been identified as the cause of both sporadic and antibiotic-associated diarrhea (AAD) (1923 ) and its role in eliciting experimental diarrhea was also confirmed (24). P. aeruginosa has been isolated from the feces of diarrheal patients with the defective immune system or who were hospitalized or received antibiotics or who had an underlying disease $(3,25,26)$. Candida spp., especially C. albicans, have been isolated as the pathogen in sporadic (27-33) as well as AAD (34), both in immunocompetent individuals and in patients with immunodeficiency (3,35-36). Antifungal treatment leads to resolution of diarrhea from Candida $(37,38)$. The role of Trichosporon in eliciting diarrhea has been documented in sporadic cases $(27,33)$, in hosts with defective immune function (35), in the immunosuppressed host (39), and in bone marrow transplanted patient who had received antifungal prophylaxis and several antibiotics (40).

In fact, opportunistic pathogens are inhabitants of human natural environment, and live in healthy individuals as part of normal flora of some parts of the body, including intestine. Conditions such as immunodeficiency, frequent or prolonged hospitalization, prophylaxis or frequent/prolonged treatment with antibiotic or antifungal agents, and the presence of an underlying disease favour pathogenicity of these organisms. Within these risk factors immunodeficiency, which was the case in our patients, per se favors pathogenicity of opportunistic agents, while other mentioned risk factors often coexist with immunodeficiency in immunocompromised hosts. Indeed, PID patients experience repeated or prolonged hospitalization which expose them to various pathogens, including opportunistic ones carried by other patients, staff, medical devices, and the environment. Moreover, due to recurrent or chronic infections and/or hema- topoietic stem cell transplantation, they receive prolonged or frequent treatment or prophylaxis with antibiotics and/or antifungals. The examples include antifungal prophylaxis in SCID patients and, after resolution of oral candidiasis, in CVID individuals $(3,23,25-41)$.

Another important factor for developing diarrhea due to opportunistic pathogens is geographical location and the climate patients occupy. The studies reporting Candida and Trichosporon as etiology of diarrhea were primarily from Asian and African countries with relatively hot climate $(28,30,32,33,41)$.

Altogether, minor differences between our results and those reported by some other studies could be attributed to these factors: 1) different sample size, 2) different antibiotic or antifungal regimens patients received, 3) different geographical locations and climate occupied by the patients, 4) some limitations in laboratory investigation of viral pathogens in our study, and 5) probably ignoring laboratory investigation of unusual organisms in some studies from countries in Europe and North America, since pathogenicity of these organisms has not yet been observed in these countries with different climate than locations occupied by some of our patients.

Accordingly, it is recommended that facultative or opportunistic pathogens to be taken into consideration in laboratory investigation of infectious etiology of diarrhea in PID, especially in the cases when no common pathogen is found, in patients who receive prophylaxis or prolonged or repeated treatment with antibiotics or antifungals, and in patients from relevant geographical locations.

\section{Conflicts of interest statement}

The authors declare that they have no conflict of interest.

\section{References}

1. Lindegren ML, Kobrynski L, Rasmussen SA, Moore CA, Grosse SD, Vanderford ML, Spira TJ, McDougal JS, Vogt RF, Jr., Hannon WH, et al. Applying public health strategies to primary immunodeficiency diseases: a potential approach to genetic disorders. MMWR Recomm Rep 2004; 53:1-29.

2. Agarwal S, Mayer L. Gastrointestinal manifestations in primary immune disorders. Inflamm Bowel Dis 2010; 16:703-711.

3. UpToDate. Aghamohammadi A, Zeinoddini A, Mohammadinejad P, Rezaei N. Gastrointestinal manifestations in primary immunodeficiency. In: UpToDate. Stiehm ER (Ed), UpToDate, Waltham, MA. (Accessed on April 14, 2015.).

4. Agarwal S, Mayer L. Diagnosis and treatment of gastrointestinal disorders in patients with primary immunodeficiency. Clin Gastroenterol Hepatol 2013; 11:1050-1063.

5. Aghamohammadi A, Mohammadinejad P, Abolhassani H, Mirminachi B, Movahedi M, Gharagozlou M, Parvaneh N, Zeiaee V, Mirsaeed-Ghazi B, Chavoushzadeh Z, et al. Primary immunodeficiency disorders in Iran: update and new insights from the third report of the national registry. J Clin Immunol 2014; 34:478-490. 
6. Conley ME, Notarangelo LD, Etzioni A. Diagnostic criteria for primary immunodeficiencies. Representing PAGID (Pan-American Group for Immunodeficiency) and ESID (European Society for Immunodeficiencies). Clin Immunol 1999; 93:190-197.

7. Vanderhoof JA. Chronic diarrhea. Pediatr Rev 1998; 19:418-422.

8. Lai KK, Lamps LW. Enterocolitis in immunocompromised patients. Semin Diagn Pathol 2014; 31:176-191.

9. Cunningham-Rundles $\mathrm{C}$, Bodian C. Common variable immunodeficiency. clinical and immunological features of 248 patients. Clin Immunol 1999; 92:34-48.

10. McCabe RP. Gastrointestinal Manifestations of Non-AIDS Immunodeficiency. Curr Treat Options Gastroenterol 2002; 5:17-25.

11. Atarod L, Raissi A, Aghamohammadi A, Farhoudi A, Khodadad A, Moin M, Pourpak Z, Movahedi M, Charagozlou M, Rezaei N. A review of gastrointestinal disorders in patients with primary antibody immunodeficiencies during a 10-year period (1990-2000), in children hospital medical center. Iran J Allergy Asthma Immunol 2003; 2:75-79.

12. Oksenhendler E, Gerard L, Fieschi C, Malphettes M, Mouillot G, Jaussaud R, Viallard JF, Gardembas M, Galicier L, Schleinitz N, et al. Infections in 252 patients with common variable immunodeficiency. Clin Infect Dis 2008; 46:1547-1554.

13. Noel J, Cubitt D. Identification of astrovirus serotypes from children treated at the Hospitals for Sick Children, London 1981-93. Epidemiol Infect 1994; 113:153-159.

14. 14. Gallimore CI, Taylor C, Gennery AR, Cant AJ, Galloway A, Iturriza-Gomara M, Gray JJ. Environmental monitoring for gastroenteric viruses in a pediatric primary immunodeficiency unit. J Clin Microbiol 2006; 44:395-399.

15. Frange P, Touzot F, Debre M, Heritier S, Leruez-Ville M, Cros G, Rouzioux C, Blanche S, Fischer A, Avettand-Fenoel V. Prevalence and clinical impact of norovirus fecal shedding in children with inherited immune deficiencies. J Infect Dis 2012; 206:1269-1274.

16. Aghamohammadi A, Fiorini M, Moin M, Parvaneh N, Teimourian S, Yeganeh M, Goffi F, Kanegane H, Amirzargar AA, Pourpak $Z$, et al. Clinical, immunological and molecular characteristics of 37 Iranian patients with X-linked agammaglobulinemia. Int Arch Allergy Immunol 2006; 141:408-414.

17. Winkelstein JA, Marino MC, Lederman HM, Jones SM, Sullivan K, Burks AW, Conley ME, Cunningham-Rundles C, Ochs HD. X-linked agammaglobulinemia: report on a United States registry of 201 patients. Medicine 2006; 85:193-202.

18. Winkelstein JA, Marino MC, Ochs H, Fuleihan R, Scholl PR, Geha R, Stiehm ER, Conley ME. The X-linked hyper-IgM syndrome: clinical and immunologic features of 79 patients. Medicine 2003; 82:373-384.

19. Brett MM, Rodhouse JC, Donovan TJ, Tebbutt GM, Hutchinson DN. Detection of Clostridium perfringens and its enterotoxin in cases of sporadic diarrhoea. J Clin Pathol 1992; 45:609-611.

20. Mpamugo O, Donovan T, Brett MM. Enterotoxigenic Clostridium perfringens as a cause of sporadic cases of diarrhoea. J Med Microbiol 1995; 43:442-445.

21. Borriello SP, Larson HE, Welch AR, Barclay F, Stringer MF, Bartholomew BA. Enterotoxigenic Clostridium perfringens: a possible cause of antibiotic-associated diarrhoea. Lancet 1984; 1:305-307.

22. Modi N, Wilcox MH. Evidence for antibiotic induced Clostridium perfringens diarrhoea. J Clin Pathol 2001; 54:748-751.

23. Asha NJ, Tompkins D, Wilcox MH. Comparative analysis of prevalence, risk factors, and molecular epidemiology of antibiot- ic-associated diarrhea due to Clostridium difficile, Clostridium perfringens, and Staphylococcus aureus. J Clin Microbiol 2006; 44:2785-2791.

24. Skjelkvale R, Uemura T. Experimental Diarrhoea in human volunteers following oral administration of Clostridium perfringens enterotoxin. J Appl Bacteriol 1977; 43:281-286.

25. Adlard PA, Kirov SM, Sanderson K, Cox GE. Pseudomonas aeruginosa as a cause of infectious diarrhoea. Epidemiol Infect 1998; 121:237-241.

26. Kim SW, Peck KR, Jung SI, Kim YS, Kim S, Lee NY, Song JH. Pseudomonas aeruginosa as a potential cause of antibiotic-associated diarrhea. J Korean Med Sci 2001; 16:742-744.

27. Talwar P, Chakrabarti A, Chawla A, Mehta S, Walia BN, Kumar L, Chugh KS. Fungal diarrhoea: association of different fungi and seasonal variation in their incidence. Mycopathologia 1990; 110:101-105.

28. Enweani IB, Obi CL, Jokpeyibo M. Prevalence of Candida species in Nigerian children with diarrhoea. J Diarrhoeal Dis Res 1994; 12:133-135.

29. Jindal N, Arora R, Bhushan B, Arora S. A study of infective aetiology of chronic diarrhoea in children in Amritsar. J Indian Med Assoc 1995; 93:169-170.

30. Chaudhury A, Nath G, Shukla B, Panda S, Singh TB. Diarrhoea associated with Candida spp.: incidence and seasonal variation. J Diarrhoeal Dis Res 1996; 14:110-112.

31. Nkuo-Akenji TK, Ndip RN, Ntoko FA. The prevalence of Candi$\mathrm{da}$ albicans-associated diarrhoea in Buea, South West Cameroon. Afr J Health Sci 2002; 9:153-157.

32. Simadibrata M, Tytgat GN, Yuwono V, Daldiyono, Lesmana LA, Syam AF, Ariawan I, Rani A. Microorganisms and parasites in chronic infective diarrhea. Acta Med Indones 2004; 36:211-214.

33. Banerjee P, Kaur R, Uppal B. Study of fungal isolates in patients with chronic diarrhea at a tertiary care hospital in north India. J Mycol Med 2013; 23:21-26.

34. Loy CE. Antibiotic-associated diarrhoea: an overlooked aetiology? Br J Biomed Sci 2005; 62:166-169.

35. Same-Ekobo A, Lohoue J, Mbassi A. (A clinical and biological study of parasitic and fungal diarrhea in immunosuppressed patients in an urban and suburban area of Yaounde). Sante 1997; 7:349-354.

36. 36. Punpoowong B, Viriyavejakul P, Riganti M, Pongponaratn E, Chaisri U, Maneerat Y. Opportunistic protozoa in stool samples from HIV-infected patients. Southeast Asian J Trop Med Public Health 1998; 29:31-34.

37. Kane JG, Chretien JH, Garagusi VF. Diarrhoea caused by Candida. Lancet 1976; 1:335-336.

38. Gupta TP, Ehrinpreis MN. Candida-associated diarrhea in hospitalized patients. Gastroenterology 1990; 98:780-785.

39. Haupt HM, Merz WG, Beschorner WE, Vaughan WP, Saral R. Colonization and infection with Trichosporon species in the immunosuppressed host. J Infect Dis 1983; 147:199-203.

40. Agirbasli H, Bilgen H, Ozcan SK, Otlu B, Sinik G, Cerikcioglu N, Durmaz R, Can E, Yalman N, Gedikoglu G, et al. Two possible cases of Trichosporon infections in bone-marrow-transplanted children: the first case of T. japonicum isolated from clinical specimens. Jpn J Infect Dis 2008; 61:130-132.

41. Colombo AL, Padovan AC, Chaves GM. Current knowledge of Trichosporon spp. and Trichosporonosis. Clin Microbiol Rev 2011;24:682-700. 